American Journal of Applied Sciences 2 (5): 1003-1007, 2005

ISSN 1546-9239

(C) Science Publications, 2005

\title{
Numerical Analysis of Pressure Pulses in the Jerk Fuel Injection Systems
}

\author{
R.A. Baker and T. Firoz \\ Automotive Focus Group, Faculty of Mechanical Engineering \\ University College of Engineering and Technology Malaysia, Locked Bag 12 \\ MEC City, 2500 Kuantan, Pahang Darul Makmur, Malaysia
}

\begin{abstract}
Computer software has been developed and described in the present study of thorough parametric analysis and design of a mechanical diesel fuel injection system. The method is based on the numerical solution of one dimensional, unsteady, incompressible flow equations through the fuel pipe along with appropriate initial condition, pump end boundary condition and nozzle end boundary condition. Method of characteristics was used to solve the mathematical model by using a finite difference technique. The computer program has been written in Visual Fortran, which is capable of calculating pressure, velocity and other related parameters at different cam angles at any location of the fuel pipe, including pump and nozzle ends. First of all the numerical scheme was optimized and then its authenticity was verified by comparing its results with calculated and measured results available in the literature. The calculations of the present software were found to have improved agreement and acceptability. It was then used to make a thorough parametric analysis of a typical fuel injection system. The results have been presented in the form of graphs.
\end{abstract}

Key words: Characteristic Method, Finite Difference, Fuel Injection System, Software Development

\section{INTRODUCTION}

A diesel fuel injector sprays an intermittent, timed and metered quantity of fuel into the engine cylinder, distributing the fuel throughout the air within and vaporizing it. Its configuration and working principle are thoroughly described in the literature ${ }^{[1,2]}$. A step by step method of analysis had very thoroughly been described as early as in 1939 by Giffen and Rowe ${ }^{[3]}$. Most of the later published works in the field are, in one way or the other, extensions and modifications of Giffen and Rowe work. A modification was proposed after nearly 20 years by Knight to make the method more suitable for digital computer ${ }^{[4]}$. Brown, et $a l^{[5]}$ had extended this method to study the effect of citations in the fuel pipe. Later, Yamaoka, et $a l^{[6]}$ extended it further for analyzing the complete fuel injection system, including the fuel supply and feed system.

A number of experimental studies on fuel injection system have also been reported in the literature. Singh and $S h a{ }^{[7]}$ have investigated and reported the effect of cam profile on the fuel pipe pressure. In an important work, Wassenaar ${ }^{[8]}$ had studied the causes and effects of secondary injection and dribbling on the high speed diesel engine performance. Lyshevskii and Shkrek ${ }^{[9]}$ have reported the method of determining injector needle valve lift pressure. The spray characteristics and their effects have been reported by Rusinov and Lavrova $^{[10]}$. A stakhov ${ }^{[11]}$ has reported the effects fuel properties, delivery pipe diameter and the presence of free air on the velocity of propagation of pressure pulses generated by the continuous jerk of the pump plunger. He had reported that the speed of propagation of the pressure pulses is a function of the elasticity of the pipe material as well as properties of the fuel used. Based on different theories, he has proposed a number of relationships of speed of pulse propagation with other properties of the pipe material like modulus of elasticity and Poison's ratio. The relationship between the rate of fuel injection and heat release was reported by Lyn and Austin ${ }^{[12]}$. Some methods of plotting fuel injection rate diagrams for high speed diesel engines have been described by Abdel Fattah ${ }^{[13]}$ while Petrook $^{[14]}$, who have reported dynamic pressure characteristics of diesel fuel injection system.

A numerical method based on the method of characteristics had been described by Streeter ${ }^{[15]}$ for the analysis of water hammer problems in pipes. As pressure pulses are continually generated by the fuel pump plunger and these pulses propagate through the fuel pipe to develop pressure at the nozzle end, the method can successfully be used to analyze the fuel injector behavior. In a similar situation, Woods ${ }^{[16]}$ had used and reported graphical method of characteristics to calculate the pressure fluctuations in the rocket motor supply pipeline.

In the present work, the authors have developed computer software to predict the pressure and velocity variations at different sections in the fuel pipe, including the fuel nozzle. A complete mathematical model, including the initial condition and pump and nozzle end boundary conditions has been developed. The method of characteristics has been used to solve the mathematical model. Giffen and Rowe's ${ }^{[3]}$ model was selected, as it gives all the significant system parameter data along with the predicted as well as 
measured pressure profiles. The data were originally available in FPS units, which has first been converted in SI units. The predicted and measured results reported in the above study, were also converted in SI units for comparison with the results by the present authors. The calculated pressure variation at the nozzle end of the present software has been plotted with respect to the cam angle. To validate the reliability of the present method, both computed and measured results reported by Giffen and Rowe have been superimposed on the same graph sheet. It was found that the pressures predicted by the present software comparatively better with the measured values. This established the reliability and superiority of the proposed method.

\section{MATHEMATICAL FORMULATION}

Finite difference solution of the momentum and continuity equations through the fuel pipe by the method of characteristics yields the following equations at the internal nodal points of the time-space mesh shown in Fig. 1 given below:

$$
\begin{aligned}
& V P_{i}=0.5\left[\begin{array}{l}
V_{i-1}+V_{i+1}+\frac{g}{s}\left(H_{i-1}-H_{i+1}\right)- \\
\frac{f . \Delta x_{1}}{2 d} \cdot\left(V_{i-1} \cdot\left|V_{i-1}\right|+V_{i+1} \cdot \mid V_{i+1}\right)
\end{array}\right] \\
& H P_{i}=0.5\left[\begin{array}{l}
H_{i-1}+H_{i+1}+\frac{s}{g}\left(V_{i-1}-V_{i+1}\right)- \\
\frac{s}{g} \frac{f . \Delta x}{2 d}\left(V_{i-1} \cdot\left|V_{i-1}\right|-V_{i+1} \cdot\left|V_{i+1}\right|\right.
\end{array}\right]
\end{aligned}
$$

VP and HP represent velocity and pressure respectively at the present time step whereas $\mathrm{V}$ and $\mathrm{H}$ are their known values one time step earlier. Subscript i represent space location. The initial condition is given as:

$\mathrm{V}=0$ and $\mathrm{H}=\mathrm{H}_{\mathrm{r}} \quad$ at $\mathrm{t}=0$

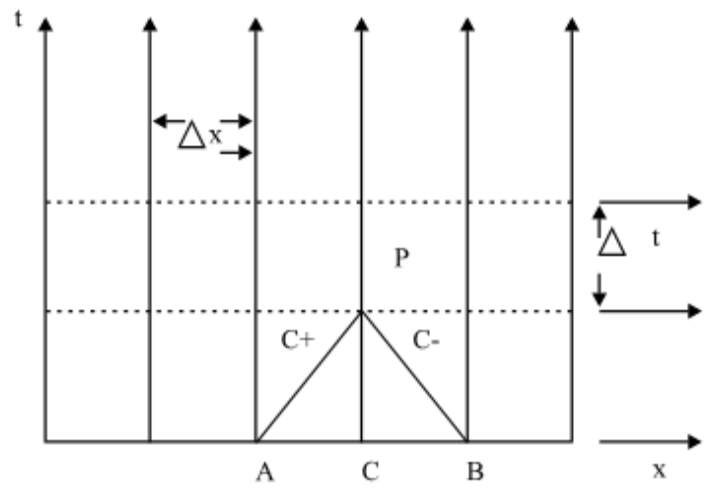

Fig. 1: Characteristic Lines on Time-Space Mesh
Mass balance at the fuel pump and mass and force balance at the nozzle end shall yield the following pump and nozzle end boundary condition equations:

$$
\begin{aligned}
V_{p p}= & \frac{A_{p l}}{A_{p}} \cdot V_{p l}-\frac{v_{p c} \cdot \rho \cdot g}{K \cdot A_{p}} \cdot \frac{d H_{p p}}{d t}- \\
& C D \cdot \frac{A_{r e l}}{A_{p}} \cdot \sqrt{2 g\left(H_{p p}-H_{a t m}\right)} \\
V_{p n}= & \frac{1}{A_{p}}\left(\frac{v_{n}}{K}+\frac{A_{n v}^{2}}{k}\right) \frac{d P_{n}}{d t}+ \\
& C D \frac{A_{n}}{A_{p}} \sqrt{2 g\left(H_{p n}-H_{c o}\right)}
\end{aligned}
$$

Each at the pump and nozzle end, one additional equation is needed to solve the two boundary conditions in two unknowns. These are achieved by $\mathrm{C}-$ and $\mathrm{C}+$ characteristics respectively and are given as:

$V P_{P}=C_{1}+C_{2} \cdot H P_{P}$

$V P_{N}=C_{3}-C_{2} \cdot H P_{N}$

Where, $C_{2}=\frac{g}{s}$

$C_{1}=V_{1}-C_{2} \cdot H_{1}+\frac{f \cdot V_{1}}{2 d} \cdot\left|V_{1}\right| \cdot \Delta t$

$C_{3}=V_{N-1}+C_{2} \cdot H_{N-1}-\frac{f \cdot V_{N-1}}{2 d} \cdot V_{N-1} \mid \cdot \Delta t$

\section{RESULTS AND DISCUSSION}

Based on the above mathematical formulation and numerical method, a computer program was written in Visual Fortran. The length of the fuel pipe was divided into ' $\mathrm{N}$ ' number of equal divisions. The explicit finite difference scheme was used to solve the equation system. To ensure a stable solution, the time step was selected to meet the current stability criterion and is given as:

$$
\Delta t \leq \frac{l}{(V+a) \cdot N}
$$


This type of calculation is found dependent on the mesh size. To establish an optimum mesh size, the results with different ' $\mathrm{N}$ ' values were first compares as shown in Fig. 2. It was found that for $\mathrm{N}>15$, there was very marginal difference in the computed results. Therefore, all the calculations were made with $\mathrm{N}=15$. As a next step, the validity of this program was checked by comparing the computed nozzle end pressures for a system available in the literature, which has reported all the requisite data as well as calculated and measured nozzle end pressures. Such a published work was found to be that of Giffen and Rowe ${ }^{[3]}$. The present authors did not come across any other studies, which have reported all the possible details for comparison sake. As the present software gives all the results in SI units, the data in the above mentioned study as well as the reported pressure variations were first converted from FPS units to SI units. The pressures calculated by the present method and those reported in the literature have been plotted in Fig. 3. A good agreement can be observed in between the three pressure plots. The pressure from the present scheme is found to have a better overall agreement with the experimental results. It is more so with regard to slight pressure drop at the beginning of the nozzle needle lift, giving a more realistic picture. The maximum pressure rise from the present calculations also agrees better with the measured values. However, some phase lag occurs that results a deviation at the end; at the time of closing of the nozzle. But, this deviation is of little significance from a practical point of view, as it does not affect the rate of fuel injection in the combustion chamber of the engine. This established the validity of the present computer software.

After the reliability and validity of the computer software were checked, it was used to make parametric analysis of the system. The effect of fuel pipe length was investigated by repeating the calculations for the original length along with other two lengths; twice and thrice respectively of the original length.

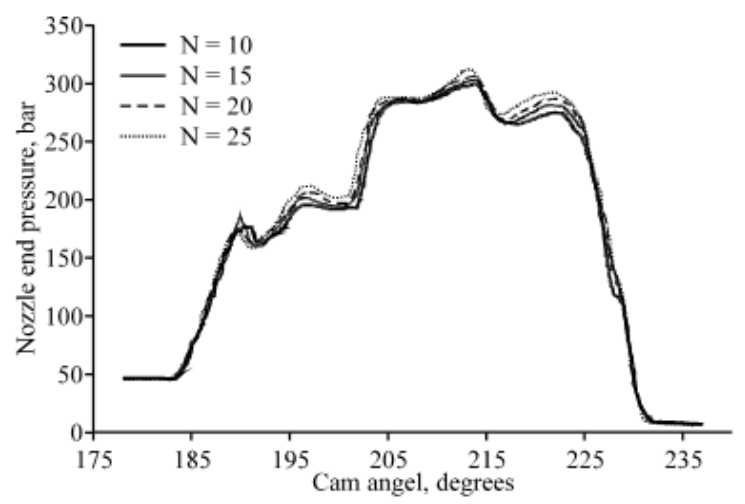

Fig. 2: Effect of Mesh Size on Computation Results

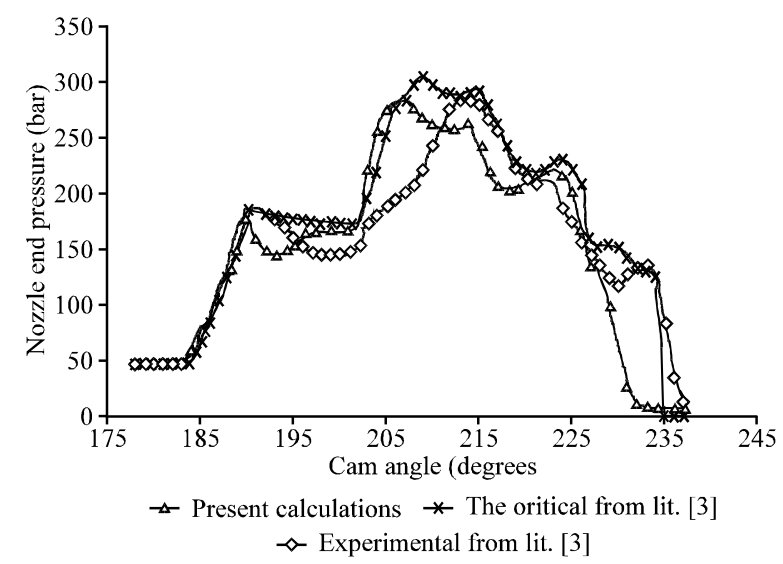

Fig. 3: Comparisons of Pressure Variations by the Present Method with the Reported Calculation and Measurement Values

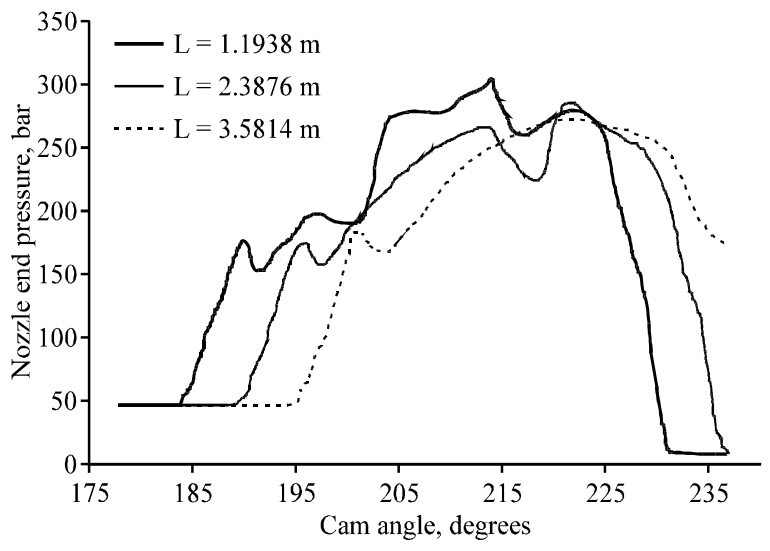

Fig. 4: Effect of Pipe Length on the Nozzle End Pressure

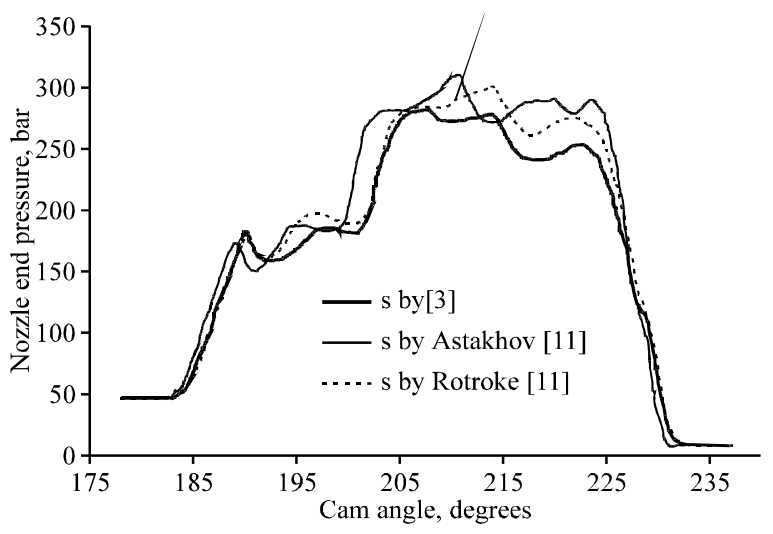

Fig. 5: Effect of Speed of Propagation of the Pressure Pulses

Results for the three pipe lengths have been plotted in Fig. 4. The increase in pipe length is found to increase the delay period. Therefore, in the design of diesel fuel injection system, the fuel pipe length is important and its optimum value must be chosen for the satisfactory functioning of the system. 


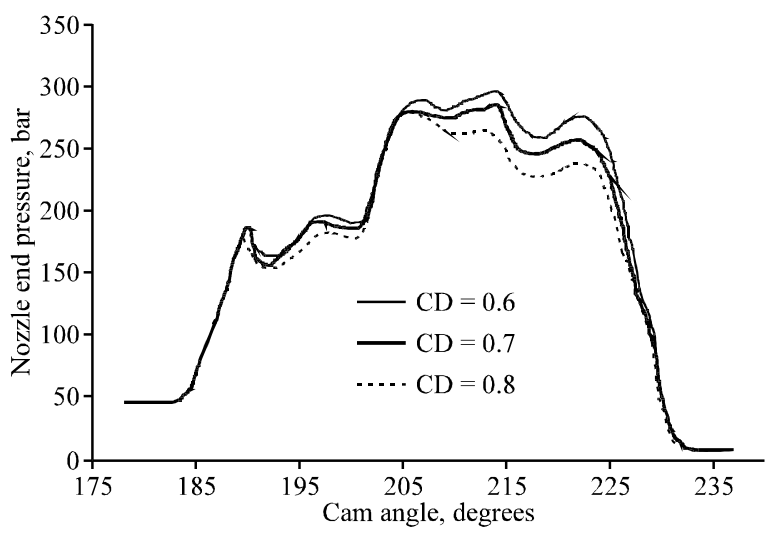

Fig. 6: Effect of Nozzle Coefficient of Discharge on the Nozzle end Pressure

The effect of speed of propagation of the pressure pulses has been plotted in Fig. 5. Its value was calculated using three different formulae available in the literature. These are given below by equation (12), defined by Giffen and Rowe ${ }^{[3]}$ and equations (13) and (14), both defined by Astakhov ${ }^{[11]}$. The results plotted in Fig. 5 reveal that the s values by equation (12) give the best results:

$$
s=c \cdot \sqrt{\frac{K \cdot g}{\rho}}
$$

$$
s=\frac{\sqrt{\frac{K \cdot g}{\rho}}}{\sqrt{1+\frac{d}{\left(d_{o}-d_{i}\right)} \cdot \frac{K}{E}}}
$$

$$
s=\frac{1}{\sqrt{\frac{\rho}{g} \cdot \frac{1}{K} \cdot \frac{2}{E}\left(\frac{d_{o}^{2}+d_{i}^{2}}{d_{o}^{2}-d_{i}^{2}}+m\right)}}
$$

The effect of the nozzle coefficient of discharge was also investigated with the help of present computer software. Three possible values $0.6,0.7$ and 0.8 were selected and the results are plotted in Fig. 6, given below. Although, there is no appreciable change in the phase lag, the peak pressure is affected by the value of the $\mathrm{CD}$. A proper value of the coefficient of discharge must therefore be used for effective design of the system.

\section{CONCLUSION}

A mathematical model has been written for a mechanical jerk type fuel injection system and it has been solved by the method of characteristics using an optimized explicit finite difference scheme. The method is dependent on time increment for a given number of pipe divisions but, it is not very critically dependent on the number of these divisions. Fifteen numbers of divisions are found to give reliable results. The computer software developed on this method is capable of computing pressure and velocity at each pipe section including the nozzle end. It was used to make a thorough parametric analysis of a given system. The effects of various parameters like pipe length speed of propagation of pressure pulses and nozzle coefficient of discharge have been studied and reported graphically.

\section{Nomenclature:}

$\mathrm{A}=$ area of cross section, $\mathrm{m}^{2}$

$\mathrm{C}=$ correlation factor

$\mathrm{CD}=$ coefficient of discharge, dimensionless

$\mathrm{D}=$ diameter, $\mathrm{m}$

$\mathrm{E}=$ modulus of elasticity of the pipe material, $\mathrm{N} / \mathrm{m}^{2}$

$\mathrm{F}=$ friction factor during fuel flow in the pipe, dimensionless

$\mathrm{G}=$ acceleration due to gravity, $\mathrm{m} / \mathrm{s}^{2}$

$\mathrm{H}=$ pressure head in the fuel pipe, $\mathrm{m}$

$\mathrm{K}=$ bulk modulus of the fuel oil, $\mathrm{N} / \mathrm{m}^{2}$

$\mathrm{K}=$ springs constant for nozzle spindle spring, $\mathrm{N} / \mathrm{m}$

$\mathrm{M}=$ Poison's ratio

$\mathrm{P}=$ pressure, $\mathrm{N} / \mathrm{m}^{2}$

$\mathrm{S}=$ velocity of pressure pulses (sound velocity) in the fuel, $\mathrm{m} / \mathrm{s}$

$\mathrm{T}=$ time, $\mathrm{s}$

$\mathrm{V}=$ velocity of fuel in the pipe, $\mathrm{m} / \mathrm{s}$

$\mathrm{V}=$ volume, $\mathrm{m}^{3}$

$\mathrm{X}=$ distance from the pump end of fuel pipe, $\mathrm{m}$

Greek letters

$\alpha=$ inclination of the fuel pipe from the horizontal

$\rho=$ mass density of fuel, $\mathrm{kg} / \mathrm{m}^{3}$

Subscripts and Superscripts

atm - atmospheric

co - combustion chamber

I - inner

$\mathrm{N}$ - nozzle

$\mathrm{NV}$ - needle valve

$\mathrm{O}$ - outer

$\mathrm{P}-$ pipe

$\mathrm{pl}$ - pump plunger

pn - pipe at the nozzle end

$\mathrm{pp}$ - pipe at the pump end

$\mathrm{R}$ - residual

rel - release port of the fuel pump

\section{REFERENCES}

1. Bosch, 1976. Automotive Handbook, $1^{\text {st }}$ English Edn, Robert Bosch GmbH.

2. Heywood, J.B., 1989. Internal Combustion Engine Fundamentals. McGraw-Hill Int. Ed, Automotive Technology Series, Singapore. 
3. Giffen, E. And A.W. Rowe, 1939. Pressure Calculations for Oil Engine Fuel Injection System, Proceedings of the Institution of Mechanical Engineers, 142: 519-534.

4. Brown, G.W. and H. McCallion, 1967-68. A simulation of an injection system with delivery pipe cavitation using a digital computer, Proc. Instn. Mech. Engrs., 182: 3.

5. Hiroyasu, H., T. Kadota and M. Arai, 1980. Supplementary Comments: Fuel Spray Characterization in Diesel Engines, In James N. Mattavi and Charles A. Amann (Eds.), Combustion Modeling in Reciprocating Engines, Plenum Press, pp: 369-408.

6. Yamaoka, K., A. Saito and M. Okazaki, 1972. Analysis of by-pass control type fuel-injection system for small diesel engine by digital computer, Bull. JSME, Vol: 15.

7. Singh, A. and K.S. Shah, 1970. Investigation on the influence of injection pressure and cam profile of fuel injection characteristics, Inst. Of Engrs. India, 51: 1-4.

8. Wassenaar, H., 1954-55. Injection phenomenon in high speed diesel engines, Proc. Automobile Div., pp: 247-266.

9. Lyshevskii, A.E. and L.Y. Shkret, 1968. Determination of dynamic pressure at initiation of nozzle lift of injector, Izv. Vys. Zav. Mas., 114: 125-31.
10. Rusinov, R.V. and M.A. Lavrova, 1966. About calculation of hydraulic characteristics (Performance curves) of diesel engine injectors, 113: 19-21.

11. Astakov, I.V., 1966. Effect of design parameters of delivery manifold and characteristics of fuel on the velocity of propagation and reflection properties of pressure waves in the fuel system of a diesel engine, Energomash, 5: 15-19.

12. Lyn, W.T. and A.E.W. Austin, 1960-61. Relation between fuel injection and heat release in a direct injection engine and the nature of the combustion process, Proc. Automobile Div., pp: 47-62.

13. Abdel Fattah, A.I.I., 1946. Injection rate diagram, some methods of obtaining these diagrams for high-speed diesel engines, Automobile Engr, 54: 101-105.

14. Petrook, W., 1960-61. The dynamic pressure characteristics of high speed diesel fuel injection equipment, J. Oil Engine and Gas Turbine, 28: 336-339.

15. Streeter, V.L., 1964. Water Hammer Analysis of Pipelines, Journal of Hydraulic Division, ASCE, Vol: 90.

16. Woods, W.A., 1961. Methods of Calculating Liquid Flow Fluctuation in Rocket Motor Supply Pipes, ARS J., pp: 1560-1567. 